\title{
Thermochemical Calorie
}

National Cancer Institute

\section{Source}

National Cancer Institute. Thermochemical Calorie. NCI Thesaurus. Code C68852.

A non-SI unit of energy equal to 4.184 joules exactly. According to the current national standard in the United States (IEEE/AST M SI 10T M 2002. American National Standard for Use of the International System of Units (SI): The Modern Metric System, New York: IEEE, 2002) the calorie in any form is not to be used. Joules should be used instead. 